\title{
Description of evandromyia spelunca, a new phlebotomine species of the cortelezzii complex, from a cave in Minas Gerais State, Brazil (Diptera: Psychodidae: Phlebotominae)
}

\author{
Gustavo ML Carvalho ${ }^{1}$, Reginaldo P Brazil ${ }^{2^{*}}$, Cristiani C Sanguinette ${ }^{1}$ and José D Andrade Filho ${ }^{1}$
}

\begin{abstract}
Background: The cave fauna of the Brazil is poorly documented, and among the insects those live or frequent caves and their adjacent environments phlebotomine sand flies call for special attention because several species are vectors of pathogens among vertebrates hosts. A new species of sand fly from Minas Gerais is described based in females and males collected in a cave of the municipality of Lassance.

Results: The morphological characters of the new species permit to include in the Evandromyia genus, cortelezzii complex. This complex consists of three species: Evandromyia corumbaensis (Galati, Nunes, Oshiro \& Rego, 1989), Evandromyia cortelezzii (Brethes, 1923) and Evandromyia sallesi (Galvao \& Coutinho, 1940).

Conclusions: The new species can be separate from the others of the cortelezzii complex through morphological characters of the male terminalia and female spermathecae.
\end{abstract}

\section{Background}

Sand flies are responsible for transmission of the genus Leishmania among vertebrates hosts and study of this insect group is of great importance in attempts to control of leishmaniasis [1]. In Brazil, the cave fauna of insects is poorly documented, and among the insects that live or frequent caves and their adjacent environments, phlebotomine sand flies call for special attention because several species are vectors of arboviruses and protozoa, among other parasites.

The geographical distribution of the sand flies species depends on their ability to adapt to different ecological niches. Thus, by its development in the immature stages and their feeding habits when adults, the species of sand flies are found where both larvae and adults can find appropriate environments for their development, including blood supply for females. In this way, the geographical distribution of species can be restricted to their access to a specific environment

\footnotetext{
* Correspondence: rpbrazil@ioc.fiocruz.br

${ }^{2}$ Departamento de Bioquímica e Biologia Molecular, Instituto Oswaldo Cruz, FIOCRUZ, Rio de Janeiro, RJ, Brazil

Full list of author information is available at the end of the article
}

and vertebrate host. Already the occurrence of leishmaniasis is basically determined by the presence of both a susceptible vector and a host/reservoir equally susceptible to the infection [2].

The growing of tourism, involving a search for natural attractions such as cave exploration, demands a better knowledge of the threats to health that people may face in those new areas.

In the present investigation a new species of sand fly from Minas Gerais is described based on both genders collected in a cave in the Lassance municipality.

\section{Methods}

Sand flies were collected using CDC light traps (HP model), conducted between June 2008 to May 2010, in the cave named "Gruta Rebenta Bombas" city of Lassance, Minas Gerais state. Sand flies were mounted in Canada balsam (males) and Berlese liquid (females), measured with a binocular Olympus $\mathrm{CH}-2$ microscope with the aid of a micrometer ocular and the drawings were done with the help of a camera lucida. All the measurements presented in this paper are given in micrometers. The nomenclature and classification is 
that proposed by Galati [3] and the abbreviation of the names for phlebotomine genera by Marcondes [4]. The new species is described based on 10 females and 10 males, which were associated by their capture in the same place at the same time as well as by the association of the morphological characteristics (antennal and palpal formulas; length association of the genital filaments; pigmentation of the thorax; and other structures) that include all the specimens of both sexes in the same genus and group.

In accordance with section 8.6 of the ICZN's International Code of Zoological Nomenclature, copies of this article are deposited at the following five publicly accessible libraries: Natural History Museum, London, UK; American Museum of Natural History, New York, USA; Museum National d'Histoire Naturelle, Paris, France; Russian Academy of Sciences, Moscow, Russia; Academia Sinica, Taipei, Taiwan.

\section{Description of Evandromyia spelunca -nov.sp. (Figures 1- 12)}

\section{Holotype male}

sand fly of medium size, measurement ca. 2,677 (2,609 $\pm 125.4 ; \mathrm{n}=10)$ in length, general colour light brown.

\section{Head (Figure 1)}

$386(370 \pm 13.9 ; \mathrm{n}=10)$ long and $262(261 \pm 10.0 ; \mathrm{n}=$ 10) wide. Head length/head width ratio 1.47: 1 (1.42 \pm $0.08 ; \mathrm{n}=10)$. Clypeus $133(129 \pm 7.1 ; \mathrm{n}=10)$ long; clypeus length/head length ratio 0.34: $1(0.35: 1 \pm 0.02 ; \mathrm{n}=$ 10). Eye $126(132 \pm 16.9 ; \mathrm{n}=10)$ long and $75(83 \pm$ $10.7 ; \mathrm{n}=10)$ wide; eye length/head length 0.33 : $1(0.36$ : $1 \pm 0.04 ; \mathrm{n}=10)$. Interocular distance $119(114 \pm 6.8 ; \mathrm{n}$ = 10). Labrum-epipharynx (LE) $218(215 \pm 5.8 ; \mathrm{n}=10)$. LE/head length 0.56: $1(0.58 \pm 0.01 ; \mathrm{n}=10)$. Labial suture forming a fork. Antenna with simple and short ascoid, not reaching the next flagellomere. Antennal formula AIII-AXV: 2 Antennomere lengths: AIII 304 (297 $\pm 10.0 ; \mathrm{n}=10) ; \operatorname{AIV} 166(155 \pm 8.4 ; \mathrm{n}=10) ; \mathrm{AV} 166$ $(157 \pm 7.5 ; \mathrm{n}=10) ; \mathrm{AXV}>\mathrm{AXVI}(\mathrm{AXV}>\mathrm{AXVI} ; \mathrm{n}=$ 7). AIII, AIV, AV, AXII, AXIII, AXIV, AXV, AXVI with papilla; ratios: AIII/head length 0.79: $1(0.80: 1 \pm 0.04 ; \mathrm{n}$ $=10)$; AIII/LE 1.39: $1(1.38: 1 \pm 0.06 ; \mathrm{n}=10)$. Palpal formula 1.4.2.3.5 (1.4.2.3.5; $\mathrm{n}=10)$. Palpomere lengths: P1 37 (36 $\pm 3.3 ; \mathrm{n}=10) ; \mathrm{P} 2146(139 \pm 4.1 ; \mathrm{n}=10) ; \mathrm{P} 3$ $173(167 \pm 6.0 ; \mathrm{n}=10) ; \mathrm{P} 4122(113 \pm 5.7 ; \mathrm{n}=10) ; \mathrm{P} 5$ $400(367 \pm 43.6 ; n=10)$. Newstead's spines inserted medially on palpomere 3 , also present on its apical third portion.

\section{Cervix}

Ventrocervical sensillae: present

\section{Thorax}

Proepimeral setae present, 4-4 [(4-4; $\mathrm{n}=2),(3-4 ; \mathrm{n}=3)$, (4-5; $\mathrm{n}=2),(3-5 ; \mathrm{n}=1),(3-3 ; \mathrm{n}=1)]$ and anepisternal superior setae present, 9-9 [(12-12; $\mathrm{n}=2),(13-13$;

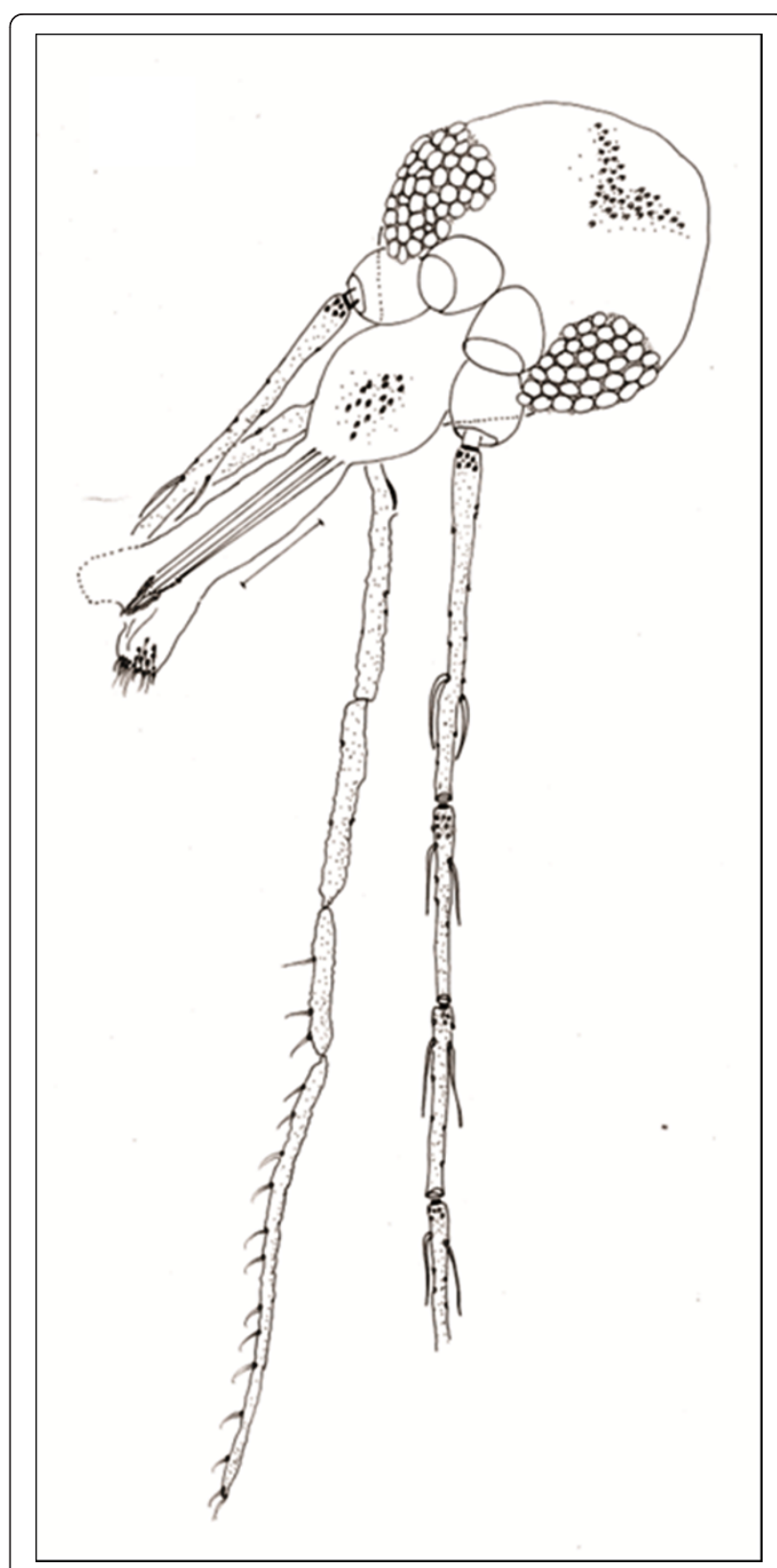

Figure 1 Evandromyia spelunca sp. nov. (Holotype male). Head, frontal view. Bar $=100 \mu \mathrm{m}$.

$\mathrm{n}=2),(9-10 ; \mathrm{n}=2),(13-14 ; \mathrm{n}=1),(10-12 ; \mathrm{n}=1),(10-$ $10 ; n=1)]$; setae on the anterior region of the katepisternum present. Wing (Figure 2) measurement 1,973 $(1,907 \pm 50.7 ; \mathrm{n}=10)$ long and $483(471 \pm 59.7 ; \mathrm{n}=10)$ at maximum width. Length/width ratio 4.08: 1 (4.05: $1 \pm$ $0.37 ; \mathrm{n}=10)$. Length of the vein sections: $\mathrm{R}_{5} 1,242$ $(1,213 \pm 29.5 ; \mathrm{n}=10)$; alpha $359(336 \pm 37.0 ; \mathrm{n}=10)$; beta $276(258 \pm 14.7 ; \mathrm{n}=10) ;$ gamma $649(625 \pm 25.4$; $\mathrm{n}=10)$; delta $41(59 \pm 25.3 ; \mathrm{n}=10)$. Legs: anterior, median and posterior, respectively: femur 731 (727 \pm 15.2; $\mathrm{n}=9), 662(690 \pm 23.6 ; \mathrm{n}=10)$ and $787(764 \pm$ 


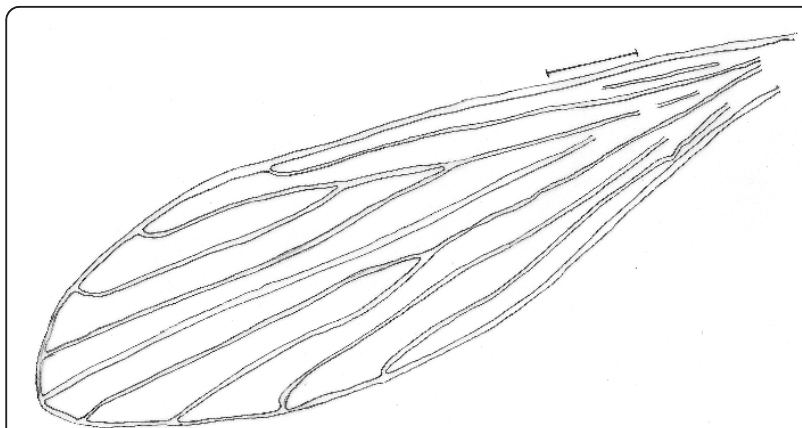

Figure 2 Evandromyia spelunca sp. nov. (holotype male). Wing. $\mathrm{Bar}=250 \mu \mathrm{m}$.

25.7; $\mathrm{n}=9)$; tibia $952(924 \pm 35.3 ; \mathrm{n}=9), 1,090(1,047 \pm$ $68.0 ; \mathrm{n}=10)$ and $1,256(1,267 \pm 17.9 ; \mathrm{n}=9)$; tarsomere I $580(560 \pm 22.1 ; \mathrm{n}=9), 635(621 \pm 18.7 ; \mathrm{n}=10)$ and $690(698 \pm 24.1 ; \mathrm{n}=9)$; tarsomeres II+III+IV+V 676 $(635 \pm 33.1 ; \mathrm{n}=9), 690(661 \pm 21.9 ; \mathrm{n}=10)$ and 745 $(718 \pm 24.4 ; \mathrm{n}=8)$.

\section{Abdomen}

terminalia (Figure 3): gonostyle $133(133 \pm 3.5 ; \mathrm{n}=10)$ long, with four spines: one apical, one upper external, inserted in a tubercle near the outer lower, which is thinner than that, and an internal implanted below the outside and with the same caliber of this. Sub terminal seta present. Gonocoxite $245(231 \pm 13.7 ; \mathrm{n}=10)$ long and $92(89 \pm 7.7 ; \mathrm{n}=10)$ wide, with a tuft containing four long and slender setae, inserted in a small tubercle, and two smaller setae, inserted beside this others. The base of the tuft presents a small pigmented area. Paramere thickened at the base, which narrows in the middle region, and widens again, taking the shape of a

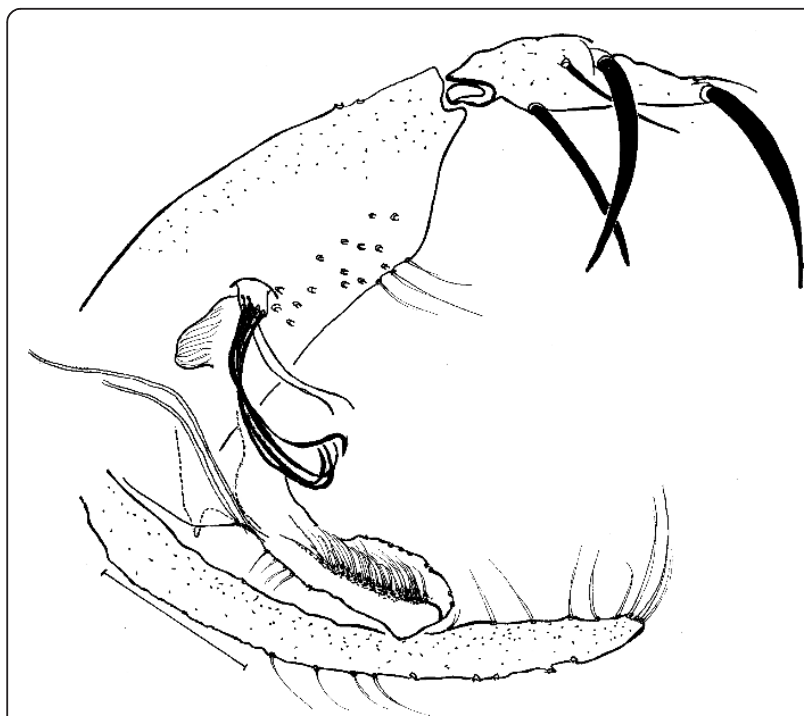

Figure 3 Evandromyia spelunca sp. nov. (holotype male). Terminalia. Bar $=100 \mu \mathrm{m}$. bird's head with the nozzle facing down. This paramere presents a suture that divides the inside and follows almost the entire length of the same. Accompanying this suture, are found setae implanted in the dorsal region. Lateral lobe $286(277 \pm 7.3 ; \mathrm{n}=10)$ long and 24 $(25 \pm 2.9 ; \mathrm{n}=10)$ wide. Lateral lobe/gonocoxite ratio 1.17: $1(1.20 \pm 0.07 ; \mathrm{n}=10)$. Conical and pigmented aedeagus. Genital filament (Figure 4) 435 (425 \pm 30.1 ; n $=10)$ long and $3.0(3.0 ; \mathrm{n}=10)$ wide and genital pump $153(150 \pm 4.5 ; \mathrm{n}=10)$. Genital filament/genital pump ratio 2.84: $1(2.83 \pm 0.22 ; \mathrm{n}=10)$. Type of genital filaments slender and beak-shaped.

\section{Allotype female}

sand fly of medium size, measuring ca. 2,567 (2,574 \pm 260.6; $\mathrm{n}=10$ ) in length. Coloration as in the males holotype and paratypes.

\section{Head (Figure 5)}

414 (422 \pm 30.6; $\mathrm{n}=10)$ long and $290(301 \pm 18.0 ; \mathrm{n}=$ 10) wide. Head length/head width ratio 1.43: 1 (1.40 \pm $0.10 ; \mathrm{n}=10)$. Clypeus $153(168 \pm 14.0 ; \mathrm{n}=10)$ long; clypeus length/head length ratio 0.37: 1 (0.40: $1 \pm 0.01$; $\mathrm{n}=10)$. Eye $133(142 \pm 10.4 ; \mathrm{n}=10)$ long and $92(85 \pm$ $9.7 ; \mathrm{n}=10)$ wide; eye length/head length $0.32(0.34: 1 \pm$ $0.03 ; \mathrm{n}=10)$. Interocular distance $143(146 \pm 17.0 ; \mathrm{n}=$ 10). Labrum-epipharynx (LE) $292(306 \pm 18.4 ; \mathrm{n}=10)$. LE/head length $0.71: 1(0.73 \pm 0.06 ; \mathrm{n}=10)$. Labial suture forming a fork. Antenna with simple and long ascoid and reaching the next flagellomere. Antennal formula AIII-AXV: 2 Antennomere lengths: AIII 235 (264 $\pm 18.8 ; \mathrm{n}=10)$; AIV $122(128 \pm 7.4 ; \mathrm{n}=10) ; \mathrm{AV} 122$ $(128 \pm 7.4 ; \mathrm{n}=10) ; \mathrm{AXV}>\mathrm{AXVI}(\mathrm{AXV}>\mathrm{AXVI} \mathrm{n}=$ 10). AIII, AIV, AXIV, AXV and AXVI with papilla; ratios: AIII/head length 0.57: $1(0.63: 1 \pm 0.05 ; \mathrm{n}=10)$; AIII/LE 0.80: $1(0.86: 1 \pm 0.06 ; \mathrm{n}=10)$. Palpal formula 1.4.3.2.5 (1.4.3.2.5; $\mathrm{n}=10)$. Palpomere lengths: P1 51 $(48 \pm 4.6 ; \mathrm{n}=10) ; \mathrm{P} 2153(158 \pm 8.1 ; \mathrm{n}=10) ; \mathrm{P} 3173$ $(177 \pm 10.8 ; \mathrm{n}=10) ; \mathrm{P} 4112(120 \pm 8.4 ; \mathrm{n}=10) ; \mathrm{P} 5442$ $(446 \pm 20.5 ; \mathrm{n}=10)$. The Newstead spines implanted in the median region of the third palpomere. Cibarium with four posterior (horizontal) teeth developed and individualized, not fused in their base. The anterior (vertical) teeth are present in greater number in the regions lateral of the cibarium, starting from the two sides of the cibarium, and forming an arch with about four teeth larger vertical, situated below the posterior teeth (Figure 6). Sclerotized area is well defined and the sclerotized arch is complete. Unarmed pharynx. Lacinia of the maxilla with 7-9 external teeth in a single longitudinal row. Cervix

Ventrocervical sensillae: present

Thorax

Proepimeral setae present, $3-4[(3-4 ; \mathrm{n}=2)(5-6 ; \mathrm{n}=3)$, (5-5; $\mathrm{n}=2),(4-5 ; \mathrm{n}=1),(4-4 ; \mathrm{n}=1)]$ and anepisternal superior setae present, $10-11[(15-15 ; \mathrm{n}=1),(20-20 \mathrm{n}=$ 


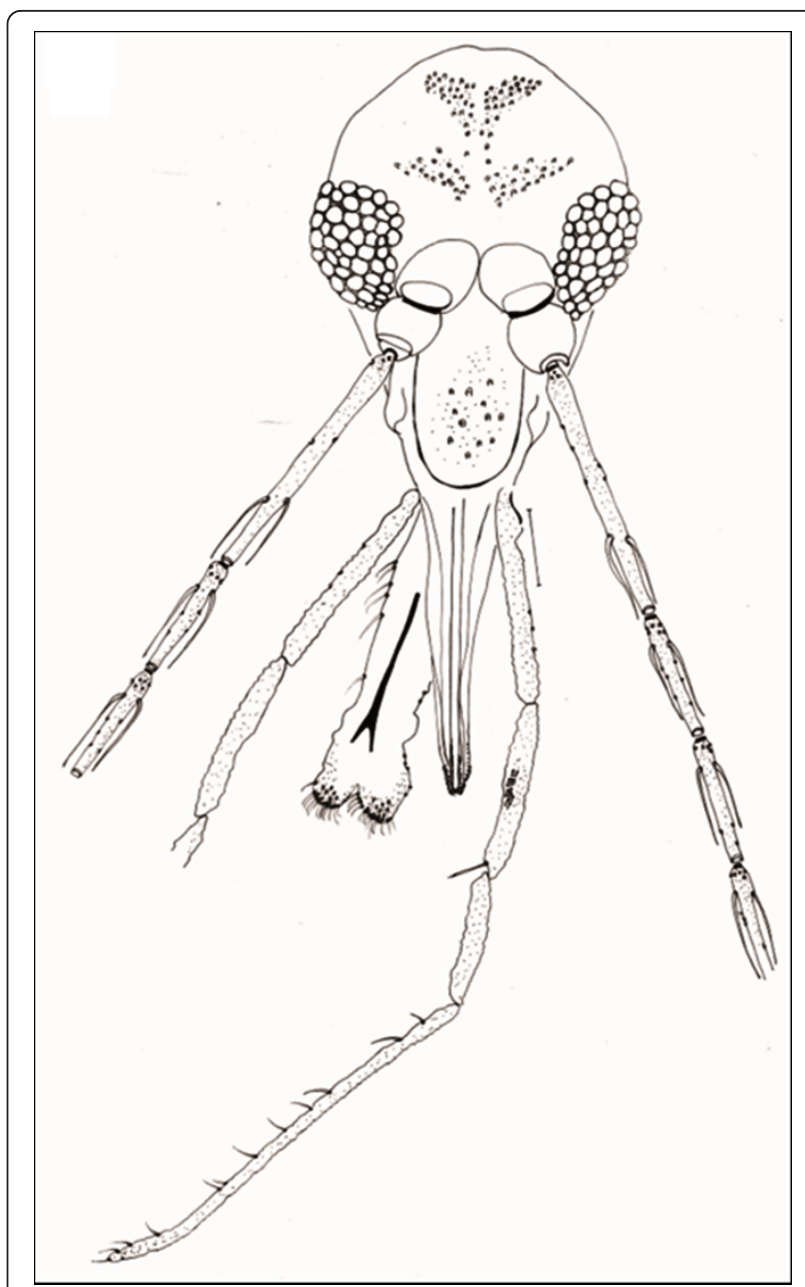

Figure 5 Evandromyia spelunca sp. nov. (Alotype female). Head, frontal view. Bar $=100 \mu \mathrm{m}$.

1), (13-14; $\mathrm{n}=1) ;(14-15 ; \mathrm{n}=1),(17-18 ; \mathrm{n}=1),(11-13 ; \mathrm{n}=$ $1),(16-17 ; n=2)]$; setae on the anterior region of the katepisternum present. Wing (Figure 7) measurement 2,029 $(2,040 \pm 141.9 ; \mathrm{n}=10)$ long and $442(558 \pm 69.1 ; \mathrm{n}=10)$ at maximum width. Length/width ratio 4.59:1 (3.66: $1 \pm$ $0.37)$. Length of the vein sections: $R_{5} 1,311(1,324 \pm 103.4$; $\mathrm{n}=10) ;$ alpha $414(439 \pm 69.9 ; \mathrm{n}=10) ;$ beta $262(266 \pm$ 28.3; n = 10); gamma 759 (755 $\pm 55.5 ; \mathrm{n}=10)$; delta 110 $(145 \pm 38.2 ; \mathrm{n}=10)$. Legs, anterior, median and posterior, respectively: femur $773(796 \pm 59.0 ; \mathrm{n}=9), 718(783 \pm$ $70.6 ; \mathrm{n}=10)$ and $828(886.6 \pm 79.2 ; \mathrm{n}=8)$; tibia $842(891$ $\pm 74.4 ; \mathrm{n}=9)$, $994(1,048 \pm 80.8 ; \mathrm{n}=4)$ and $1,229(1,273 \pm$ 100.7; $\mathrm{n}=8)$; tarsomere I $511(570 \pm 61.5 ; \mathrm{n}=9)$ ), $593(625$ $\pm 38.4 ; \mathrm{n}=10)$ and $690(716 \pm 33.3 ; \mathrm{n}=7)$; tarsomeres II $+\mathrm{III}+\mathrm{IV}+\mathrm{V} 662(652 \pm 56.7 ; \mathrm{n}=9), 649(687 \pm 56.2 ; \mathrm{n}=$ $10)$ and $690(735 \pm 49.6 ; \mathrm{n}=7)$.

\section{Abdomen}

spermathecae (Figure 8$): 20(20 \pm 1.7 ; \mathrm{n}=10)$ long by $17(17 ; \mathrm{n}=10)$ at maximum width. The body of the
Figure 4 Evandromyia spelunca sp. nov. (holotype male). Genital pump and filaments. Bar $=100 \mu \mathrm{m}$. 


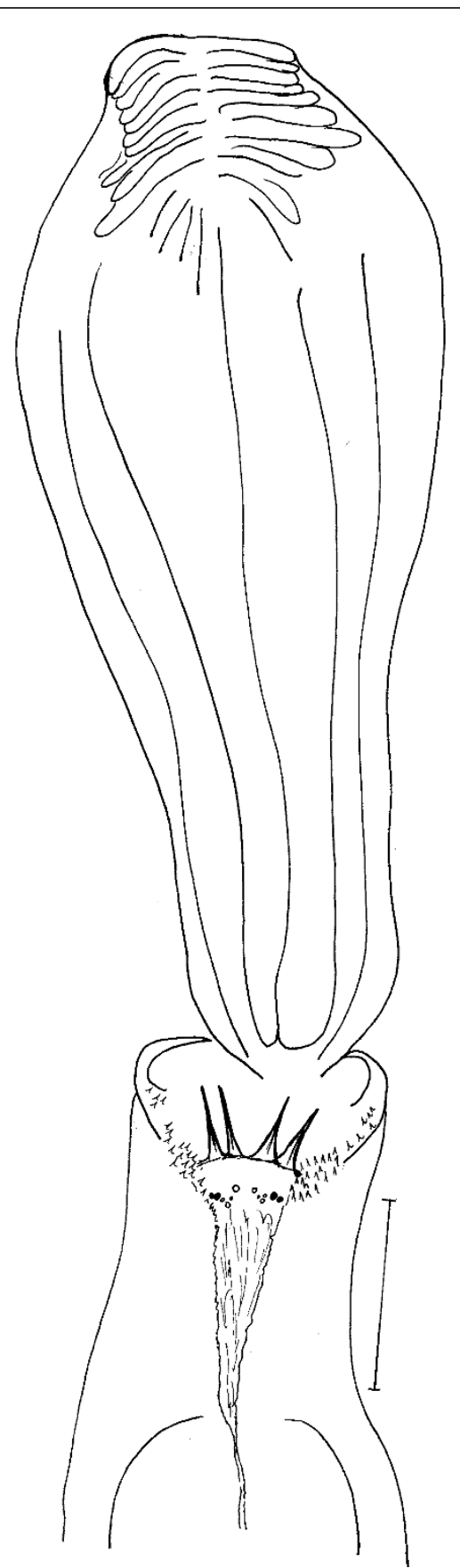

Figure 6 Evandromyia spelunca sp. nov. (paratype female) Pharynx and cibarium. Bar $=100 \mu \mathrm{m}$.

spermatheca is globular with diameters approximately equals to the others of group. The head of the spermathecae present some fine bristles inserted in the apex. The individual and common sperm ducts are smoothwalled, the latter being short compared to the first. The individual duct is $197(199 \pm 12.4 ; \mathrm{n}=8)$ in length and the common duct $47(48 \pm 2.7 ; \mathrm{n}=8)$. Cercus $119(125$ $\pm 15.7 ; \mathrm{n}=10$ ) long.

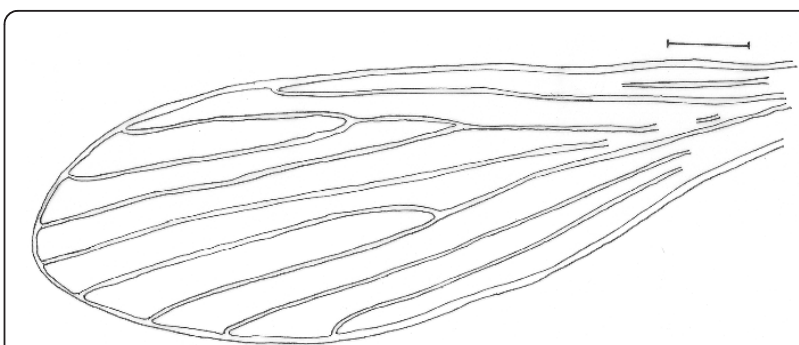

Figure 7 Evandromyia spelunca sp. nov. (paratype female). Wing. Bar $=250 \mu \mathrm{m}$.

\section{Type-material}

Hotype male (N. 89,458) and allotype female (N. 87,358) collected respectively on $30^{\text {th }}$ September 2009 and $26^{\text {th }}$ June 2008 with CDC light traps, model HP, in a limestone cave named "Gruta Rebenta Bombas", municipal district of Lassance, Minas Gerais state, Brazil (Carvalho, G.M.L. and colleagues), together with nine male paratypes (N. 87,715 collected on 28/08/2008; N. 89,459 to N.89,464 collected on 3009 2009;N.89,465 collected on $26 / 05 / 2009$ and 89,466 collected on 10/03/2010) and nine female paratypes (N. 86,800 collected on 17/04/ 2008; 86,970; and 87,011 collected on 21/05/2009; 87,$158 ; 87,233 ; 87,367 ; 87,368$ collected on $26 / 06 / 2008$; 87,403 and 87,405 collected on $26 / 05 / 2008$ ). The typematerial is deposited in the "Coleção de Flebotomíneos" of the "Instituto René Rachou/FIOCRUZ", Belo Horizonte, Brazil.

\section{Etymology}

The name Evandromyia spelunca sp. nov. has been given in regards to the meaning of cave in Latin.

\section{Results and Discussion}

The morphological characters of the new species permit included in the Evandromyia genus, in the cortelezzii complex. This complex consists of three species: Evandromyia corumbaensis (Galati, Nunes, Oshiro \& Rego, 1989), Evandromyia cortelezzii (Brethes, 1923) and Evandromyia sallesi (Galvão \& Coutinho, 1940). These species are morphologically close and often confused, causing errors in its specific identification [5].

The males of the genus Evandromyia present the gonocoxite with a tuft of bristles, basal and compact; the paramere is simple or branched; the lateral lobe apex is thin and the females present the relationship between the lengths: clypeus/head wider than $1 / 3$; eye/ head less than $1 / 2$; and spermathecae, with variable body. The cortelezzii complex belongs to the cortelezzi series of the Barretomyia subgenus. This series presents as main morphological characteristics: males, with the paramere and aedeagus simple; the gonostyle with upper external spine implanted in his middle, and lower spine, inserted in the basal third. Females with the globular 


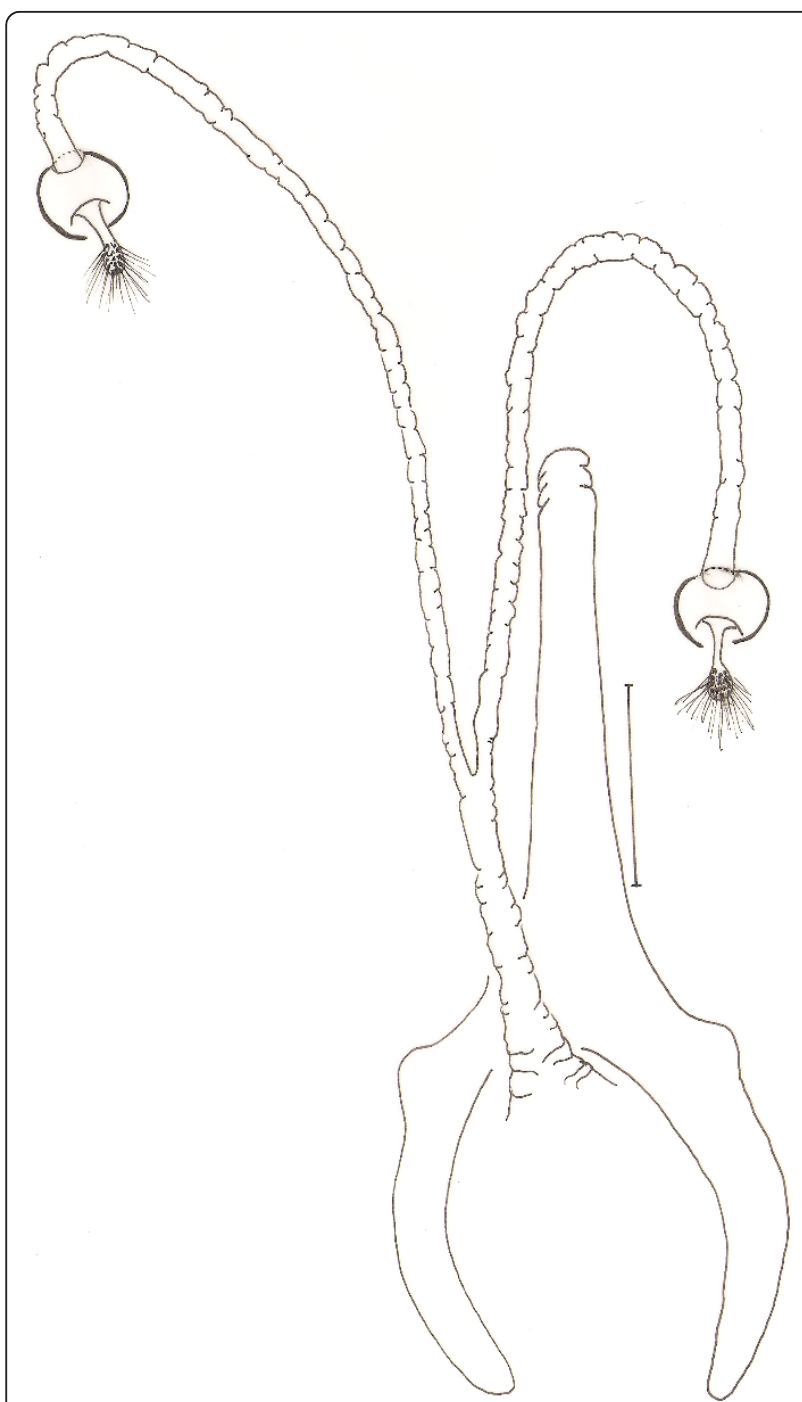

Figure 8 Evandromyia spelunca sp. nov. (paratypes female). Spermathecae. Bar $=100 \mu \mathrm{m}$.

spermathecae's body and the individual ducts are tubular [3]. Evandromyia edwardsi (Mangabeira, 1941) also belong to this series.

The new species can be separated from others of the cortelezzii complex through morphological characters. All the males of the complex are very close being separated by the following characteristics: paramere, which provides more similar aspect to Ev. cortelezzii and Ev. sallesi, however, with the internal suture, the curvature and the shape of the paramere, being enough to separate the new species from the other two closer (see Figures 3, 9 and 10). Ev. sallesi presents the paramere with the most consistent shape compared to all other species, so being the most robust (Figure 9). The suture that divides the inside of the paramere is more central and follows almost the entire length of paramere in the new

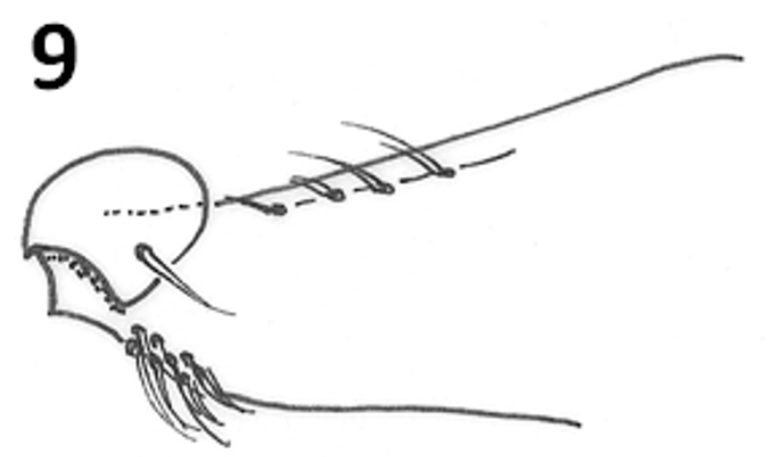

Figure 9 Evandromyia sallesi - Paramere. Bar $=100 \mu \mathrm{m}$.

species. This is more evident in the parameres of the $E v$. cortelezzii and Ev. corumbaensis, the latter being the thinnest and convex paramere of all species of the complex (Figure 11). The lateral lobe is slightly longer than all other species of the complex. The base of the tuft presents a small pigmented area, being this characteristic common to the three other species of the cortelezzii complex. But with the tuft of the gonocoxite in the new species being slightly different from the others three species of the complex, which provides a more similar aspect to Ev. corumbaensis, both separated by the aspect of the bristles, more thinner in Ev. corumbaensis, and the tubercle that presents less setae in the new species.

The separation of the females from the others of the complex is more confused, and was not always possible, usually when the spermathecae are not present or totally visible. However, the new species can be separated from the Ev. cortelezzii and Ev. sallesi (Figure 12) by spermathecae and characteristics of their ducts: individual and common, which are noticeably longer in the new species (Figure 8) and more similar to Ev. corumbaensis. Only characteristics of the cibarium were not enough to

10

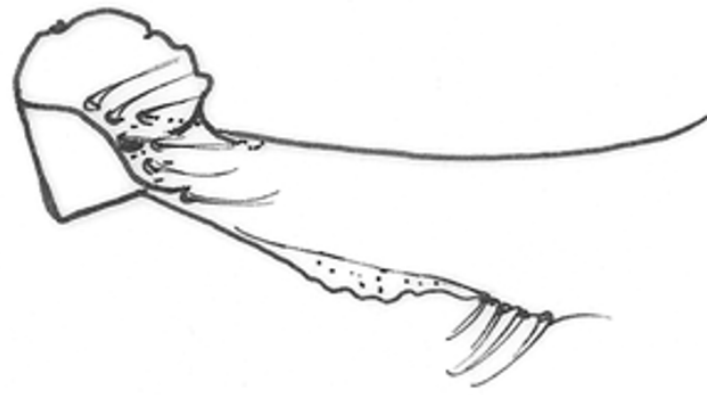

Figure 10 Evandromyia cortelezzii - Paramere. Bar $=100 \mu \mathrm{m}$. 


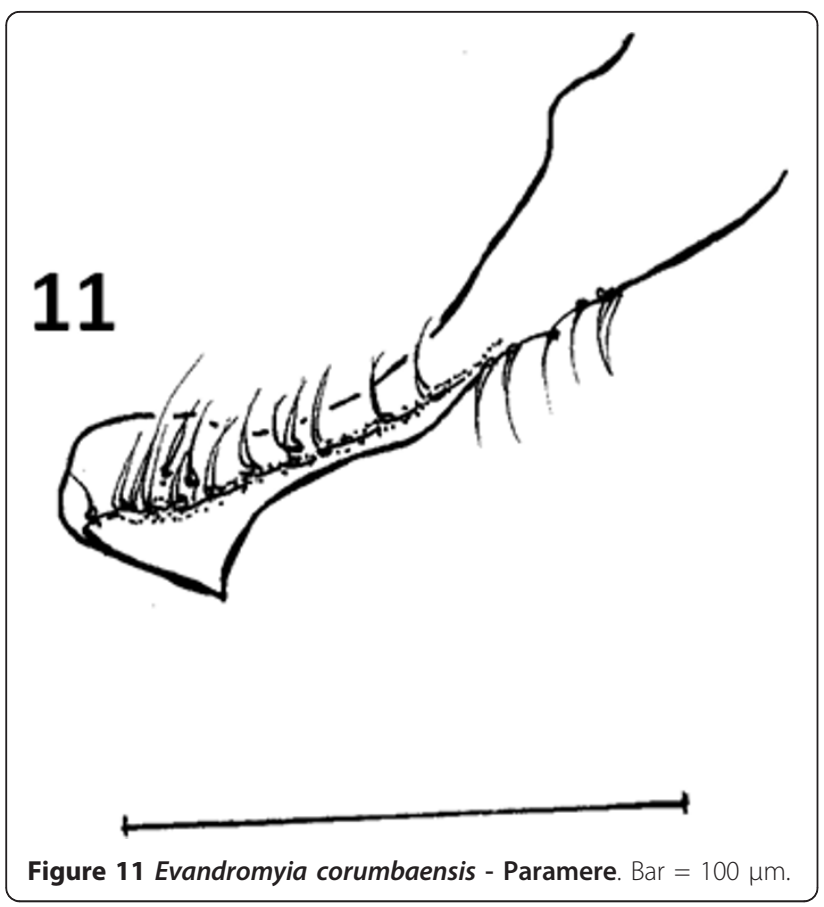

separate the females of the complex. We can utilize characteristics of the cibarium to separate the species of the complex, observing the distance between the vertical teeth implantation, and position of the arch that form the horizontal teeth, this distance being greater in the new species. Added to this, it is important to check the layout of vertical teeth in the new species, which appears in the form of an arc, starting at the sides of cibarium, from top to bottom, which usually causes the

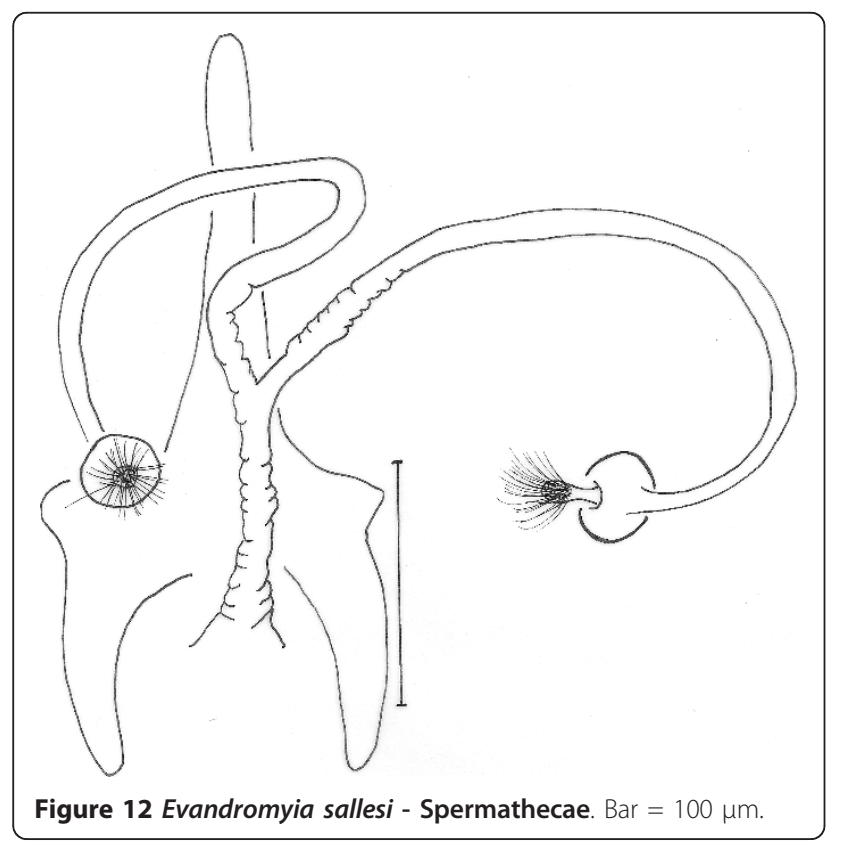

distance between the deployments mentioned above, higher in Ev. spelunca sp. nov.

Due to the difficulty of identifying the species of this complex, it became routine, with rare exceptions [6], to use geographic distribution for identify them in Brazilian regions. However, it was recently demonstrated that the three species of the complex occur in all states of the Center-west Region, and only Ev. corumbaensis is restricted to that region. The species of this complex that present the greater distribution in the country is Ev. cortelezzii, demonstrating its omission from the lists of species in several states due Ev. sallesi, which has more restricted distribution than the one quoted in the literature [7]. Thus, we do not suggest the use of geographic distribution to identify the species of this complex, but we can suggest the observation of its occurrence in caves, beyond the morphological characteristics, since the new species had their captures practically restricted to inside the cave studied, showing preference for this environment.

It is still important to emphasize that the new species is sympatric with Ev. sallesi inside or outside the cave, however the latter one are always captured inside the cave in less number than outside the cave (data not shown).

\section{Conclusions}

The present study adds a new species, namely Ev. spelunca sp. nov., to the Brazilian phlebotomine sand fly fauna, presenting characters for its separation from members of the cortelezzii complex, to which it belongs With the description of the new species, now the cortelezzii complex contains 4 species, belonging to the cortelezzii series of the Barretomyia subgenus, Evandromyia genus.

\section{Author details}

${ }^{1}$ Coleção de Flebotomíneos, Centro de Referência Nacional e Internacional para Flebotomíneos, Instituto René Rachou, FIOCRUZ, Av. Augusto de Lima 1715, 30190-002 Belo Horizonte, MG, Brazil. ${ }^{2}$ Departamento de Bioquímica e Biologia Molecular, Instituto Oswaldo Cruz, FIOCRUZ, Rio de Janeiro, RJ, Brazil.

\section{Authors' contributions}

GMLC, RPB, CCS and JDAF participated in morphological analysis and taxonomic discussion of the specimens. GMLC and CCS did drawing and measurements of the new species. GMLC, JDAF and RPB drafted the manuscript. All authors read and approved the final version of the manuscript.

\section{Competing interests}

The authors declare that they have no competing interests.

Received: 13 April 2011 Accepted: 9 August 2011

Published: 9 August 2011

\section{References}

1. Killick-Kendrick R: Phlebotomine vectors of the leishmaniasis: a review. Med Vet Entomol 1990, 4:1-24.

2. Gontijo CMF, Melo MN: Leishmaniose Visceral no Brasil: quadro atual, desafios e perspectivas. Rev Bras Epidemiol 2004, 7:338-349. 
3. Galati EAB: Classificação de Phlebotominae. In Flebotomíneos do Brasil. Edited by: Rangel EF, Lainson R. Rio de Janeiro, Fiocruz; 2003:23-53.

4. Marcondes CB: A Proposal of generic and subgeneric abbreviations for phlebotomine sandflies (Diptera: Psychodidae: Phlebotominae) of the world. Entomol News 2007, 118:351-356.

5. Galati EAB, Nunes VLB, Oshiro ET, Rego FA Jr: Nova espécie de Phlebotominae, Lutzomyia corumbaensis, sp. n. (Diptera, Psychodidae) do complexo Lutzomyia cortelezzii. Rev Bras Entomol 1989, 33:765-475.

6. Rangel EF, Azevedo AC, Andrade CA, Souza NA, Wermelinger ED: Studies on sandfly fauna (Diptera: Psychodidae) in a foci of cutaneous leishmaniasis in Mesquita, Rio de Janeiro State, Brazil. Mem Inst Oswaldo Cruz 1990, 85:39-45.

7. Carvalho GML, Brasil RP, Falcão AL, Andrade Filho JD: Geographical distribution of the cortelezzii complex (Diptera: Psychodidae: Phlebotominae) from Brazil. Neotropical Entomology 2009, 38:876-879.

doi:10.1186/1756-3305-4-158

Cite this article as: Carvalho et al: Description of evandromyia spelunca, a new phlebotomine species of the cortelezzii complex, from a cave in Minas Gerais State, Brazil (Diptera: Psychodidae: Phlebotominae).

Parasites \& Vectors 2011 4:158.

\section{Submit your next manuscript to BioMed Central} and take full advantage of:

- Convenient online submission

- Thorough peer review

- No space constraints or color figure charges

- Immediate publication on acceptance

- Inclusion in PubMed, CAS, Scopus and Google Scholar

- Research which is freely available for redistribution

Submit your manuscript at www.biomedcentral.com/submit 